Research Article

\title{
Effect of Pulsed Jet on Pore Pressure of Deep Formation Rock
}

\author{
Yong Wang $\mathbb{D},{ }^{1}$ Hongjian Ni $\mathbb{D},{ }^{1}$ Ruihe Wang, ${ }^{1}$ Peng Lei, ${ }^{2}$ Bin Huang, ${ }^{1}$ Shubin Liu, \\ and Ning $\mathbf{L i}^{3}$ \\ ${ }^{1}$ School of Petroleum Engineering, China University of Petroleum (East China), Qingdao 266580, China \\ ${ }^{2}$ Well Testing Branch of CNPC Bohai Drilling Engineering Company Limited, Langfang 065007, China \\ ${ }^{3}$ PetroChina Tarim Oilfield Company, Korla 841000, China
}

Correspondence should be addressed to Hongjian Ni; nihj@upc.edu.cn

Received 5 November 2021; Accepted 20 December 2021; Published 29 December 2021

Academic Editor: fan feng

Copyright (C) 2021 Yong Wang et al. This is an open access article distributed under the Creative Commons Attribution License, which permits unrestricted use, distribution, and reproduction in any medium, provided the original work is properly cited.

Pulsed jet significantly affects the pore pressure of deep formation and then affects the mechanical ROP. In this paper, the effect of jet pulsation on deep pore pressure in the formation is studied by the finite element method. Under the pulsed jet, the maximum relative negative pressure is along the wellbore axis, and the farther it is to the borehole axis, the smaller the relative negative pressure is. With the increase of pulse frequency, the relative negative pressure increases and the maximum point of relative negative pressure moves upward. The optimum pulse frequency is from $50 \mathrm{~Hz}$ to $500 \mathrm{~Hz}$. There is a linear relationship between pulse amplitude and relative negative pressure.

\section{Introduction}

Pulsed jet drilling technology is proposed based on conventional jet drilling technology. The technology of raising rate of penetration (ROP) is applied in many aspects such as downhole pressurization and ultra-high-pressure jet [1]. Pulsed jet uses limited bottomhole hydraulic energy to produce local pulse negative pressure and impact force and to clean rock debris and change rock stress [2]. Wells and Bizanti experimentally and theoretically studied the effects of jet turbulence and fluctuation on carrying capacity of drilling fluid and concluded that the turbulence and fluctuation can improve carrying capacity of drilling fluid $[3,4]$. By studying the pulsed jet nozzle, Xiong [5] theoretically analyzed the rock cleaning mechanism of pulsed jet and concluded that pulsed jet can reduce the chip hold-down effect.

Drilling technology assisted by pulsed jet has developed greatly [6-10]. But its research focuses on the field of impact crushing of rock [11-13] and numerical simulation of selfexcited oscillation [14-18]. In conventional drilling, to balance the deep formation pressure, the fluid column pressure is higher than the pore pressure in the formation.
Fluid column pressure has a "chip hold-down effect" on the rock debris. This makes it difficult to leave the bottom of the well and results in repeated cutting of the rock debris by the bit. Pulsed jet can generate pressure pulsation in deep formation and cause local pore pressure variation. Therefore, the study of local pore pressure variation law of deep formation rock caused by pulsed jet at bottom of the well is helpful to reveal the accelerating mechanism of pulsed jet assisted rock breaking.

Most research studies on pore pressure focus on the stress distribution of borehole wall and analysis of factors affecting borehole stability [19-21]. Elastoplastic mechanics and pore elasticity mechanics are used to analyze the mechanical mechanism of borehole instability. In elastic-plastic mechanics, displacement and stress methods are used to solve the displacement and stress of rock [22], ignoring the pore fluid migration. It is considered that the system is in static equilibrium, the stress, strain, and displacement are functions of spatial coordinates, independent of time, and the calculated distribution of stress can be regarded as a stable solution after borehole excavation. There are relatively few studies on the distribution of stress at the bottom of the well. Warren and Smith [23] studied the influence of average 
stress changes of rock at the bottom of the well on ROP. Ito et al. [24] studied the influence of stress concentration phenomenon at the bottom of the well on borehole collapse. Considering the fluid-structure coupling, the bottom of the well is divided into three-dimensional tension stress zone, three-dimensional compression stress zone, and tension and compression stress zone according to the stress in literature [25-28]. The dynamics of the bottom stress is ignored in the above research, and the time is also an important factor affecting stress distribution.

\section{Numerical Model}

The variation law of deep pore pressure in the formation under pulsed pressure is difficult to be measured by indoor test simulation, and the field test is more difficult. At present, finite element software has made some progress in the application of seepage problems such as groundwater pumping, geothermal exploitation, nuclear waste treatment, and reservoir-induced earthquake. We can obtain the variation of pore pressure of any position with the method and comprehensively grasp the variation law of downhole seepage field. Therefore, the variation of pore pressure at the bottom of the well is analyzed by the finite element method. Simulations were conducted by using Abaqus.

2.1. Governing Equation. From the virtual work principle and the governing equation of pore fluid, the equilibrium equation and continuity equation in geotechnical medium can be obtained as follows [29]:

$$
\begin{aligned}
& \int_{V} \sigma: \delta \varepsilon d V=\int_{s} t \cdot \delta v d S+\int_{V} f \cdot \delta v d V+\int_{V}\left(s n+n_{t}\right) \rho_{w} g \cdot \delta v d V, \\
& \int\left[\delta u _ { w } \left(\frac{\rho_{w}}{\rho_{w}^{0}}\left(s n+n_{t}\right)-\frac{1}{J}\left(\frac{\rho_{w}}{\rho_{w}^{0}} J\left(s n+n_{t}\right)_{t}\right)+\Delta t \int s \delta u_{w} \frac{\rho_{w}}{\rho_{w}^{0}} s n n \cdot v_{w}, d S+\Delta t \frac{k_{s}}{\rho_{w}^{0} g} \frac{\partial \delta u_{w}}{\partial x} \cdot k \cdot\left(\frac{\partial u_{w}}{\partial x}-\rho_{w} g\right) d V=0,\right.\right.
\end{aligned}
$$

where $t$ is the surface force, $f$ is the volume force except free water, $\delta \varepsilon$ is the virtual strain rate, $\delta v$ is the virtual velocity, $s$ is the saturation, $n$ is the effective porosity, $n_{t}$ is the trap porosity, $\rho^{0} w$ is the initial pore fluid density, $\rho w$ is the pore fluid density, $\delta u_{w}$ is the virtual displacement, $k$ is the permeability coefficient of saturated rock, and $k_{s}$ is the permeability coefficient.

Discretizing the above equation by the finite element method, the relevant equilibrium equation and continuity equation can be obtained as

$$
\begin{aligned}
K^{M N} \bar{c}_{\delta}^{N}-L^{M P} \bar{c}_{u}^{P} & =P^{M}-I^{M} \\
\left(\widehat{B}^{M Q}\right)^{T} \bar{v}^{M}+\widehat{H}^{Q P} \bar{u}^{P} & =Q^{Q}
\end{aligned}
$$

It is assumed that the pore fluid changes from $t$ to $t+\Delta t$ :

$$
\bar{\delta}_{t+\Delta t}^{N}=\bar{\delta}_{t}^{N}+\Delta t\left\{(1-\varsigma) \bar{v}_{t}^{N}+\varsigma \bar{v}_{t+\Delta t} .\right.
$$

Hypothesize $\varsigma=1$, and the backward difference is

$$
\bar{v}_{t+\Delta t}=\frac{1}{\Delta t}\left(\bar{\delta}_{t+\Delta t}^{N}-\bar{\delta}_{t}\right)
$$

Thus, the pore fluid equation at time $t+\Delta t$ is

$$
-\left(B^{M Q}\right)^{T} \bar{c}_{\delta}^{M}+\Delta t H^{Q P} \bar{c}_{u}^{P}=\Delta t\left[-Q_{t+\Delta t}^{Q}+\left(\widehat{B}^{M Q}\right)^{T} \bar{v}_{t+\Delta t}^{M}+\widehat{H}^{Q P} \bar{u}_{t+\Delta t}^{P} .\right.
$$

The equation can be solved with the equilibrium equation.

2.2. Physical Model. Analysis shows that the borehole is considered as a regular cylinder, and it is an axisymmetric structure. Based on the borehole axis, a cylindrical formation with a diameter of $2 \mathrm{~m}$ and a length of $2 \mathrm{~m}$ was selected as the research object. The borehole diameter is $215.9 \mathrm{~mm}$, and its length is $1 \mathrm{~m}$. In addition, to improve the accuracy of the analysis without increasing the scale of the model, a quarter of the model is simulated by the symmetry method.
The simulation process is described as follows. The initial pore pressure in the formation is first applied to face 1. After it becomes stable, the fluid column pressure is applied to face 2 and face 3 . When pulsed jet drilling is used, the fluid column pressure with pressure fluctuation is applied to face 3. The model and boundary conditions are shown in Figure 1.

Analysis shows that the pore pressure near the borehole wall changes sharply. Therefore, the grid near the borehole wall is densified during grid division. The scale of the grid after division is 53120. The relevant grid division results are shown in Figure 2. 


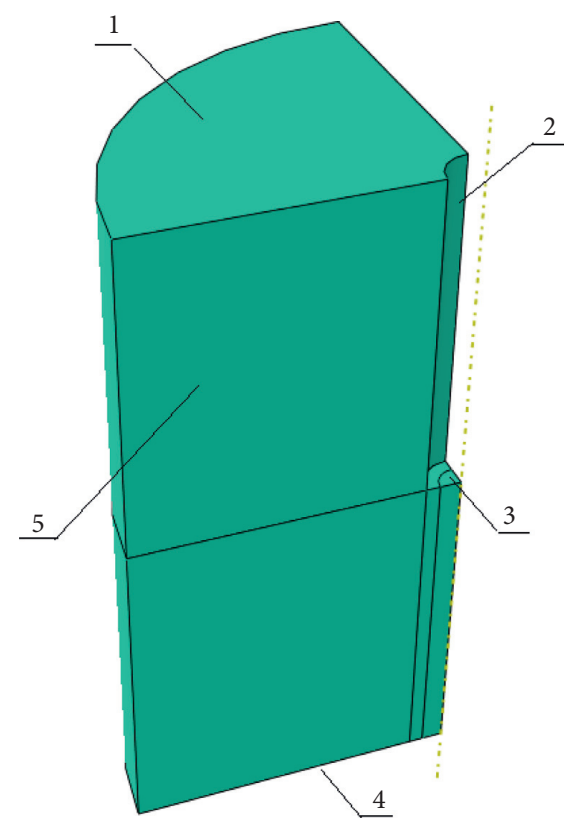

Figure 1: Physical model: 1, initial pore pressure application surface; 2, pressure surface of drilling fluid column; 3 , impulsive pressure application surface; 4 , restraint surface; and 5 , symmetry plane.

Assuming that the underground rock mass is an elastomer, the material parameters are shown in Table 1.

\subsection{Basic Assumptions}

(1) The rock is a porous medium, and the pores are evenly distributed in the rock mass.

(2)Rock pores are saturated with fluid.

(3) In the range of this model, the void ratio and permeability coefficient of rock are constants.

(4) The pressure transmission between pore fluid and drilling fluid in the formation is smooth and in accordance with Darcy's law.

(5) Borehole's irregularity and deviation are not considered.

\section{Characteristic Analysis of Pore Pressure in Bottom Hole Rock}

Figure 3 shows a cloud diagram of pore pressure distribution when the initial pore pressure is $40 \mathrm{MPa}$, the fluid column pressure is $46 \mathrm{MPa}$, and the permeability coefficient is $1 \times 10^{-8} \mathrm{~m} / \mathrm{s}$. The figure shows that the pressure at the borehole wall and bottom of wellbore is the highest. The pore pressure gradually attenuates from and bottom to the formation. When it is $0.1 \mathrm{~m}$ away from the well bore, the pressure attenuation is more than $50 \%$, when it is $0.5 \mathrm{~m}$ away from the well bore, the pressure attenuation is more than $90 \%$, and when it is $0.8 \mathrm{~m}$ away from the well bore, the formation pressure is initial pore pressure. It shows that the effective influence scope of fluid column pressure on pore pressure in the formation is $0.5 \mathrm{~m}$.

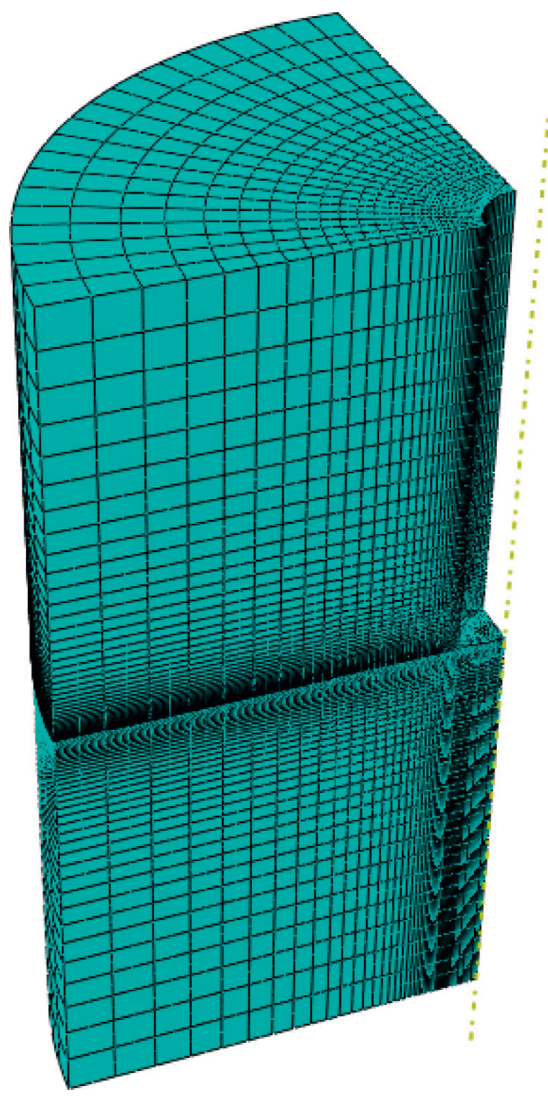

Figure 2: Mesh.

Figure 4 shows the vertical pressure attenuation of four different locations on the bottom of the well. The curve in the figure shows that the pressure attenuates rapidly in the beginning and gradually slows down later. The pressure attenuation law of these points is similar, but the initial attenuation along the axis of the wellbore is the slowest, and the attenuation at the edge of the bottom wellbore is the fastest. Over $0.1 \mathrm{~m}$ from bottom hole, the attenuation below the wellbore axis is relatively fast, and the attenuation at the edge of the bottom wellbore is relatively slow. When it is $0.4 \mathrm{~m}$ from the bottom of the well, the pore pressure is almost the same at this position, and the pressure is about $40.5 \mathrm{MPa}$. The curve in the figure shows that the pore pressure attenuation along the axis of wellbore is relatively slow, the "chip hold-down effect" caused by the drilling fluid column is relatively low, and the rock debris is relatively easy to leave the bottom of the well. The rock debris on the wellbore wall is more difficult to leave the wall than that at the axis of wellbore due to the rapid pore pressure attenuation, and rock debris is more likely to be crushed repeatedly here.

Figure 5 shows the attenuation along the wellbore axis in two cases: (1) initial pore pressure is $5 \mathrm{MPa}$, fluid column pressure is $11 \mathrm{MPa}$, and permeability coefficient is $1 \times 10^{-8} \mathrm{~m} / \mathrm{s}$ and (2) initial pore pressure is $40 \mathrm{MPa}$, fluid column pressure is $46 \mathrm{MPa}$, and permeability coefficient is $1 \times 10^{-8} \mathrm{~m} / \mathrm{s}$. It is found that when the initial pore pressure is different, the attenuation law of pore pressure in the formation is the same. It is concluded that initial pore pressure does not affect pore pressure attenuation. 
TABLE 1: Material parameters.

\begin{tabular}{lccccc}
\hline Elastic modulus $(\mathrm{Pa})$ & Poisson's ratio & Void ratio & Permeability coefficient $\left(\mathrm{m}^{*} \mathrm{~s}^{-1}\right)$ & Density $\left(\mathrm{g} / \mathrm{cm}^{3}\right)$ & Pore fluid density $\left(\mathrm{g} / \mathrm{cm}^{3}\right)$ \\
\hline $73 \times 10^{9}$ & 0.25 & 0.25 & $1 \times 10^{-8}$ & 5 & 1
\end{tabular}

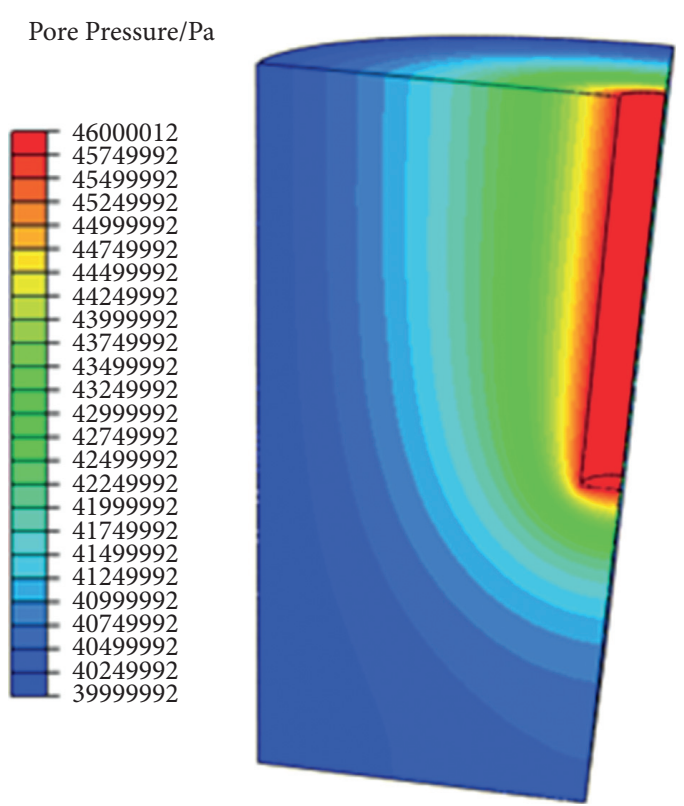

FIgURE 3: The distribution of pore pressure.

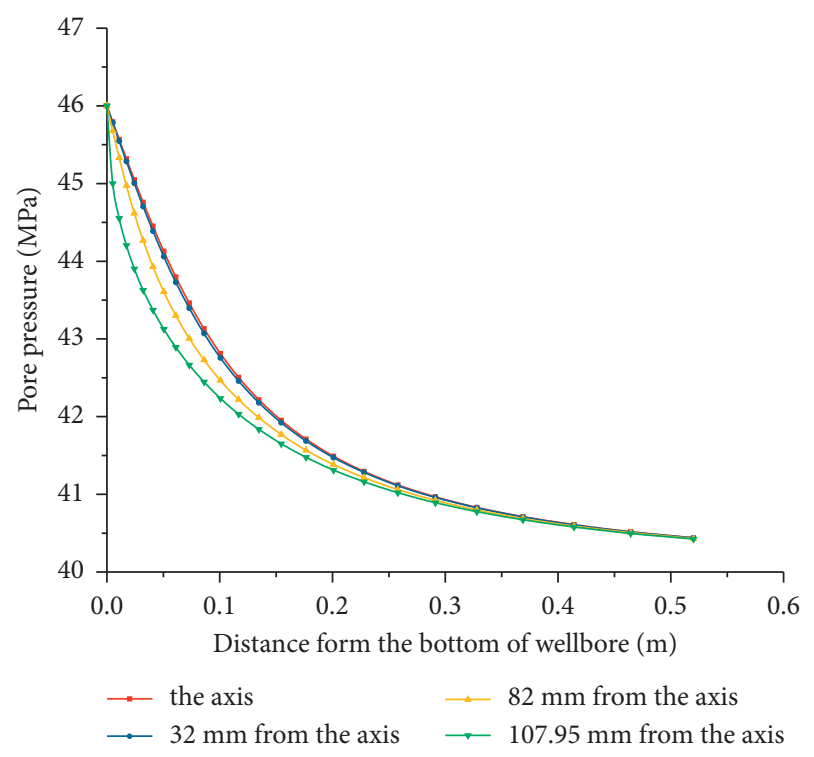

FIGURE 4: Attenuation law of pore pressure.

Figure 6 shows the effect of formation permeability coefficient on pore pressure in the formation when the initial pore pressure is $40 \mathrm{MPa}$ and the fluid column pressure is $46 \mathrm{MPa}$. The curve in the figure shows that when permeability coefficients are different, the attenuation law and attenuation amplitude of pore pressure in the formation along the borehole axis are also similar. It indicates that the

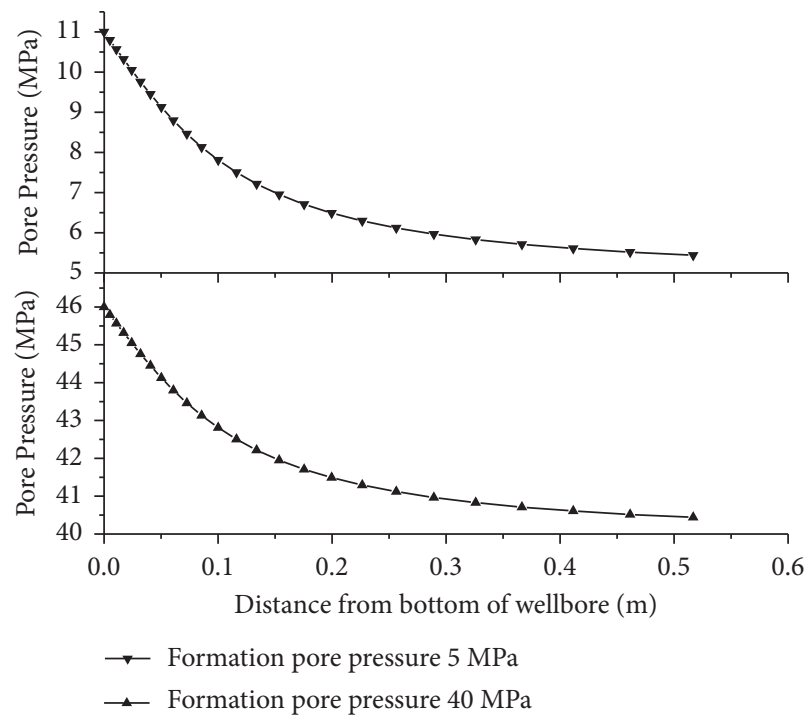

Figure 5: The effect of initial pore pressure on pore pressure attenuation.

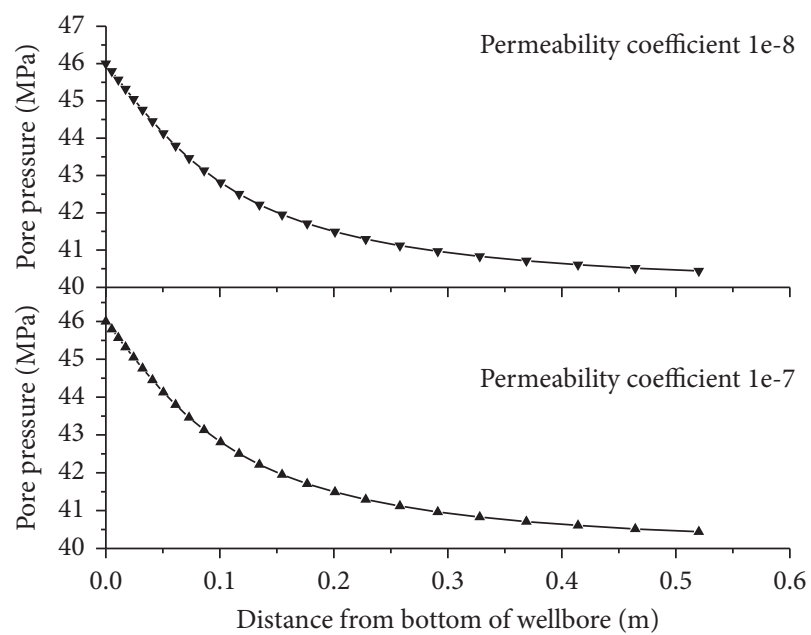

Figure 6: The effect of permeability coefficient on pore pressure.

initial pore pressure and permeability coefficient have little effect on the attenuation of bottom hole pore pressure with the stable liquid column pressure.

\section{Analysis of Pore Pressure in Deep Rock with Pulsed Jet}

When bottom hole pressure fluctuates, the main factors affecting the local pore pressure of bottom hole formation are pulse frequency, pulse amplitude, initial pore pressure, and permeability coefficient. 
4.1. Pulse Frequency. To study the effect of pulse frequency on the attenuation law, it is assumed that (1) the permeability coefficient is $1 \times 10^{-8} \mathrm{~m} / \mathrm{s}$; (2) the loading curve is sinusoidal; (3) the amplitude is $1 \mathrm{MPa}$; (4) the initial pore pressure in the formation is $40 \mathrm{MPa}$; and (5) the fluid column pressure is $46 \mathrm{MPa}$. The attenuation law of deep pore pressure in the formation with pulsed jet at different frequencies is analyzed in Figure 7.

Figure 7 shows that the pore pressure in the formation increases first and then decreases along the axis of the wellbore, and the influence depth of frequency on the pore pressure in the formation is $20 \mathrm{~mm}$. When the frequency is $5 \mathrm{~Hz}$, the maximum pore pressure is at $10 \mathrm{~mm}$ from the bottom of the well, which is $45.45 \mathrm{MPa}$; when the frequency is $50 \mathrm{~Hz}$, the maximum pore pressure is at $5.18 \mathrm{~mm}$, which is $45.86 \mathrm{MPa}$; when the frequency is $500 \mathrm{~Hz}$, the maximum pore pressure is at $5.18 \mathrm{~mm}$, which is $46.07 \mathrm{MPa}$; when the frequency is $5000 \mathrm{~Hz}$, the maximum pore pressure is at $5.18 \mathrm{~mm}$, which is $46.11 \mathrm{MPa}$. It shows that with the increase of frequency, the maximum pore pressure difference gradually increases, but the increase of amplitude gradually slows down, and the difference between $500 \mathrm{~Hz}$ and $5000 \mathrm{~Hz}$ is relatively small. When the pulse frequency is higher, it will generate larger relative negative pressure at the bottom of the well.

Figure 8 shows the cyclic variation of the difference between the bottom hole pressure and the maximum pore pressure along the axis. By observing the curve in the figure, it is found that the pressure difference increases in the first $1 / 4 \mathrm{~T}$, decreases in $1 / 4$ to $3 / 4 \mathrm{~T}$, and increases in $3 /$ $4 \mathrm{~T}$ to $\mathrm{T}$. the whole curve is similar to the loading curve, which is a sinusoidal variation; when the pulse amplitude is constant, the time length of reducing the original "chip hold-down effect" is gradually shortened with the increase of frequency, and the relative negative pressure is gradually enhanced. The greater the negative pressure difference between bottom hole pressure and pore pressure in the formation is, the easier it is to overturn the rock debris at bottom hole and the fewer the repeated cutting of rock debris is. In drilling, the length of negative pressure time is also an important factor to evaluate the pulsation effect. The longer the relative negative pressure time is, the more it is conducive to improve the rock breaking efficiency. Through comprehensive analysis of these two factors, it can be concluded that $50-500 \mathrm{~Hz}$ frequency is more suitable for drilling.

4.2. Pulse Amplitude. The permeability coefficient is assumed to be $1 \times 10^{-8} \mathrm{~m} / \mathrm{s}$, the loading curve is sinusoidal, the frequency is $50 \mathrm{~Hz}$, the initial pore pressure in the formation is $40 \mathrm{MPa}$, and the fluid column pressure is $46 \mathrm{MPa}$. The attenuation law of pore pressure of bottom hole formation under different amplitudes is analyzed, as shown in Figure 9. It is found that the pulse amplitude mainly affects the bottom hole pressure and has little effect on the maximum pore pressure in the formation; when the amplitude is $0.5 \mathrm{MPa}$ and $1 \mathrm{MPa}$, the maximum pore pressure of the formation appears at $5.18 \mathrm{~mm}$ below the bottom of the well, and when

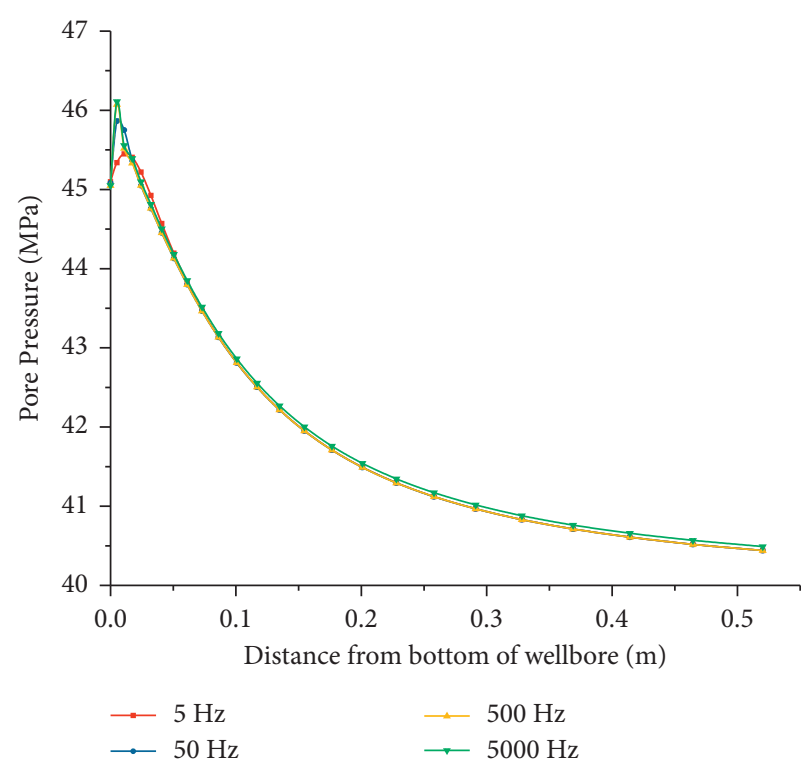

Figure 7: The effect of pulse frequency on pore pressure.

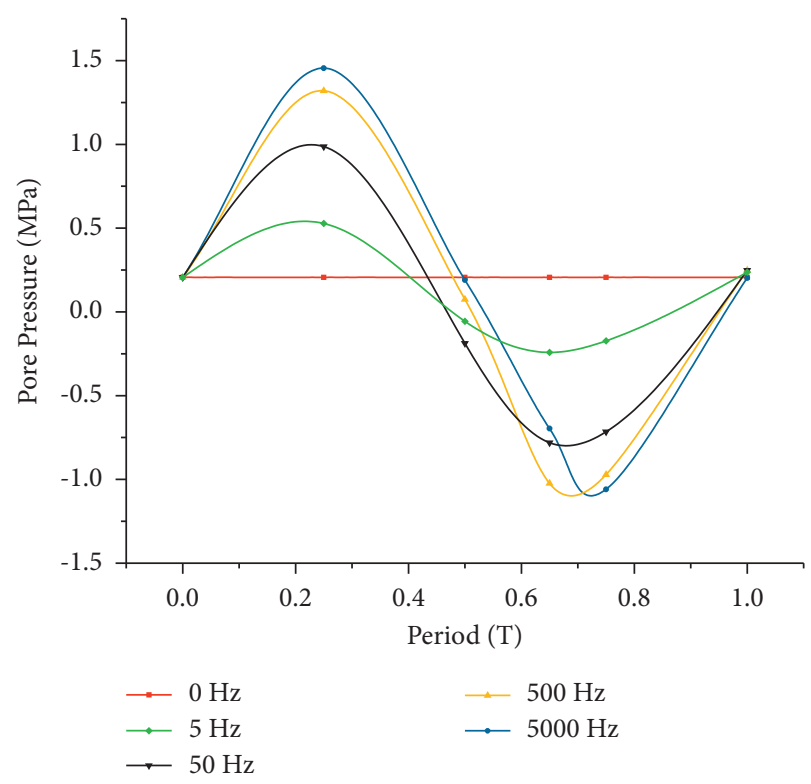

FIgURE 8: The effect of pulse frequency on pore pressure.

the amplitude is $1.5 \mathrm{MPa}$ and $2 \mathrm{MPa}$, the maximum pore pressure of the formation appears at $10.9 \mathrm{~mm}$. Thus, it mainly affects the pressure difference at the surface of the well.

Figure 10 shows the variation of pore pressure difference with pulse amplitude. When the pulse amplitude is $0.5 \mathrm{MPa}$, $1 \mathrm{MPa}, 1.5 \mathrm{MPa}$, and $2 \mathrm{MPa}$, the difference between bottom hole pressure and pore pressure in the formation is $-0.28 \mathrm{MPa},-0.74 \mathrm{MPa},-1.23 \mathrm{MPa}$, and $-1.71 \mathrm{MPa}$, respectively. The results show that with the increase of pulse amplitude, the relative negative pressure produced underground gradually increases and changes approximately linearly. It can be concluded that the large downhole pressure pulsation is beneficial to ROP. 


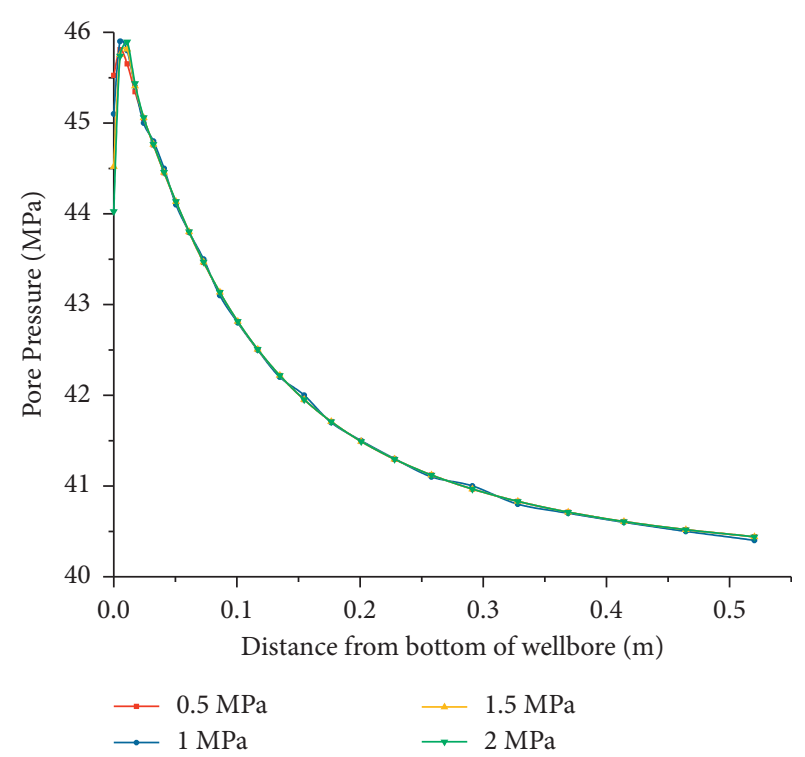

FIgURE 9: The effect of pulse amplitude on pore pressure.

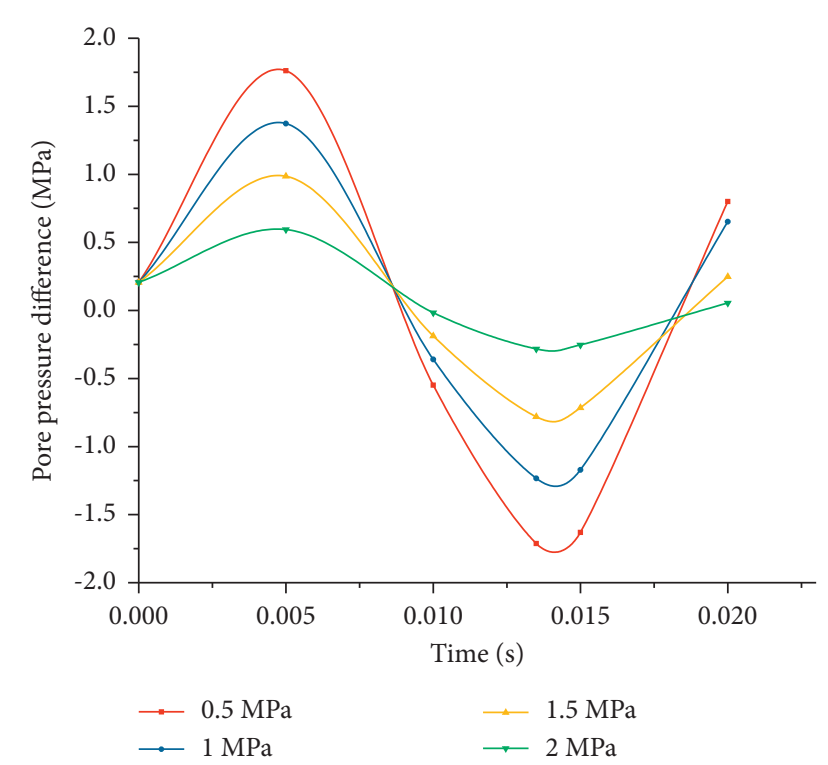

Figure 10: The pressure difference under different pulse amplitudes.

4.3. Initial Pore Pressure. The pore pressure in the formation is assumed to have a permeability coefficient of $1 \times 10^{-8} \mathrm{~m} / \mathrm{s}$, the loading curve is sinusoidal, the frequency is $50 \mathrm{~Hz}$, and the difference between fluid column pressure and formation initial pore pressure is $6 \mathrm{MPa}$. The attenuation law of pore pressure in the formation at the bottom of the well with different initial pore pressure is analyzed, as shown in Figure 11.

The curve shows that the initial pore pressure of the formation only changes the initial value of the pore pressure, and the relative negative pressure difference between the bottom hole and the formation is the same. It shows that when pulsation

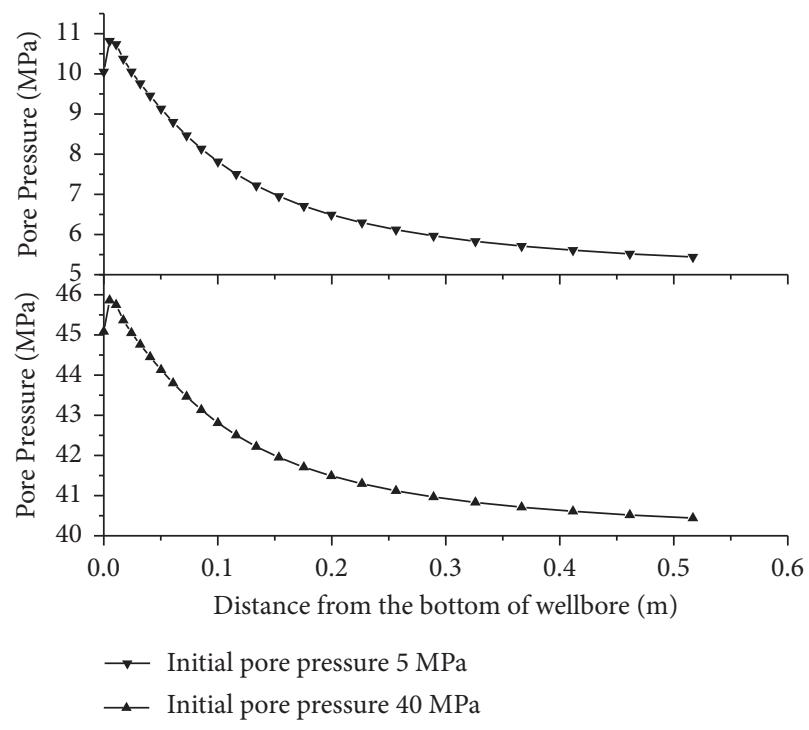

FIgURE 11: The effect of initial pore pressure on pore pressure attenuation.

frequency and amplitude are the same, only the initial pore pressure of the well is different, and the relative negative pressure at the bottom of the well is the same. It can be considered that the initial pore pressure of the formation has no effect on the attenuation of the pore pressure.

4.4. Permeability Coefficient. Assuming that a sinusoidal pressure pulsation with a frequency of $50 \mathrm{~Hz}$ and an amplitude of $1 \mathrm{MPa}$ is applied to the bottom of the well, the fluid column pressure is $46 \mathrm{MPa}$, and the initial pore pressure difference of the formation is $40 \mathrm{MPa}$. Figure 12 shows the effect of permeability coefficient on pore pressure in the formation attenuation when other conditions remain unchanged. The curve in the figure shows that the influence scope of permeability coefficient on the pore pressure is $20 \mathrm{~mm}$. When the permeability coefficient is $1 \times 10^{-8}$, the maximum pore pressure appears at $5.18 \mathrm{~mm}$, which is $45.86 \mathrm{MPa}$; when the permeability coefficient is $2 \times 10^{-8}$, the maximum pore pressure appears at $10.09 \mathrm{~mm}$, which is $45.68 \mathrm{MPa}$; when the permeability coefficient is $5 \times 10^{-8}$, the maximum pore pressure appears at $11 \mathrm{~mm}$, which is 45.57 $\mathrm{MPa}$; when the permeability coefficient is $1 \times 10^{-7}$, the maximum pore pressure appears at $13.45 \mathrm{~mm}$, which is 45.39 $\mathrm{MPa}$. It is indicated that the relative negative pressure of bottom hole and formation pores gradually slows down with the increase of permeability coefficient. The position of the maximum pore pressure gradually moves down with the increase of permeability coefficient, and the influence scope gradually increases.

Figure 13 shows the variation of pore pressure difference with permeability coefficient. The curve of relative negative pressure on bottom hole is like the pulse amplitude curve, but with the increase of permeability coefficient, the relative negative pressure decreases gradually. 


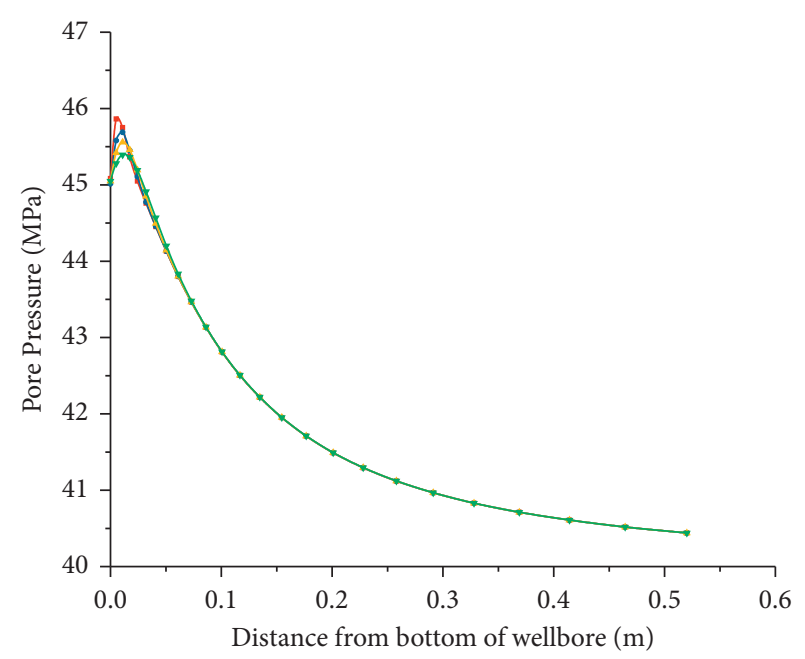

Permeability coefficient

\begin{tabular}{|c|c|}
\hline$=1 \mathrm{e}-8$ & $\longrightarrow$ \\
\hline$\rightarrow 2 \mathrm{e}-8$ & $\rightarrow$ \\
\hline
\end{tabular}

FIGURE 12: The effect of permeability coefficient on pore pressure attenuation.

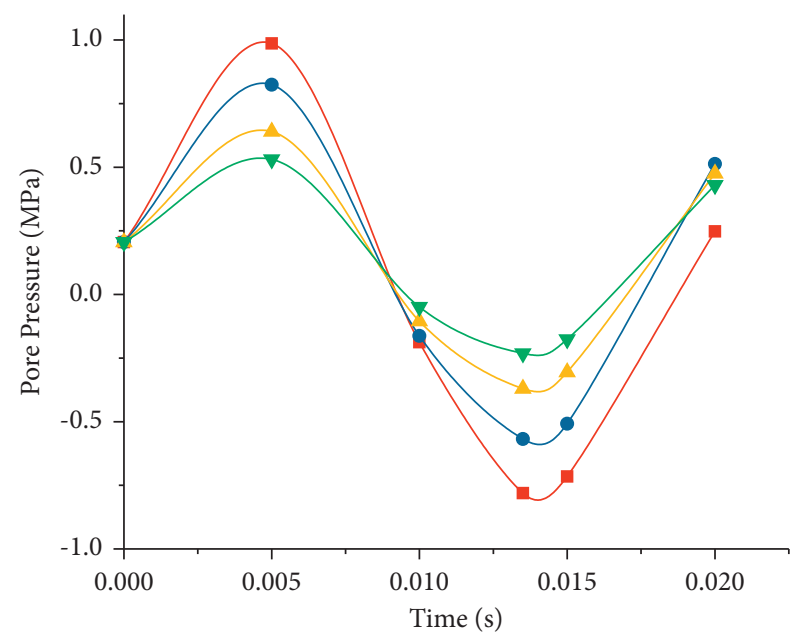

Permeability coefficient

$$
\because 1 \mathrm{e}-8 \quad \longrightarrow 5 \mathrm{e}-8
$$$$
\rightarrow 2 \mathrm{e}-8 \quad \longrightarrow 1 \mathrm{e}-7
$$

Figure 13: The effect of permeability coefficient on pressure difference.

\section{Mechanism of Pulsed Jet Raising ROP}

Whether the rock debris can be removed in time has a significant impact on the ROP. If rock debris is not separated from the rock matrix, the fluid column pressure is $P_{b}$, the pore pressure in the formation is $P_{p}$, and the pressure of the jet acting on the bottom of the well is $\Delta P_{j}$. Currently, the normal pressure on the rock debris is $P_{b}+\Delta P_{j}+w$, where $w$ is the weight of the rock debris. Since the debris is not yet separated from the rock matrix, the pressure in the crack between the debris and its matrix can be approximately taken as $P_{p}$. When $P_{b}+\Delta P_{j}+w>P_{p}$, the rock debris will be

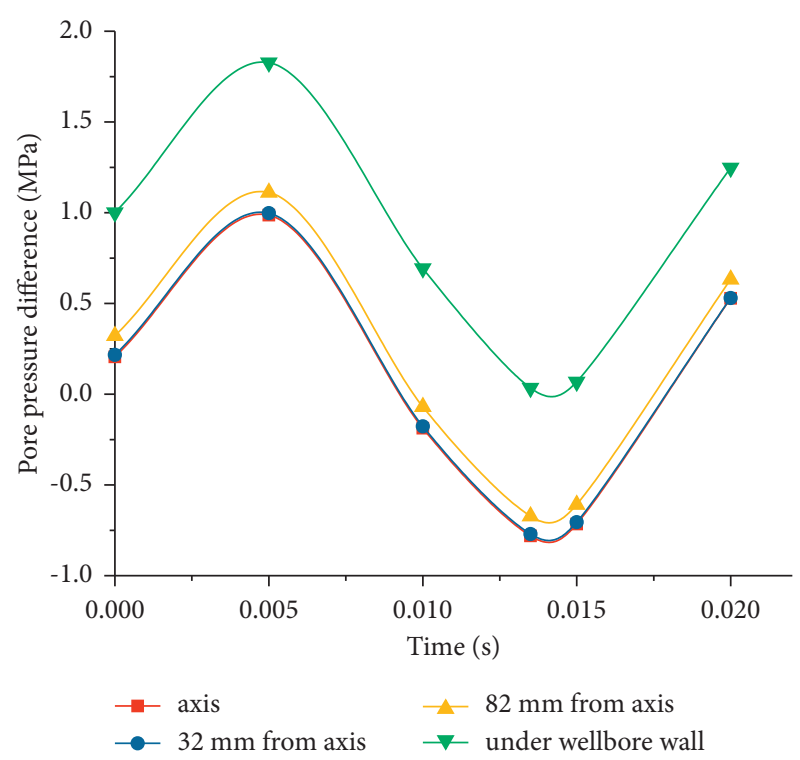

FIgURE 14: Pore pressure difference in different positions.

held at the bottom of the well. To separate the rock debris from the bottom of the well, a horizontal load $T$ must be applied to the rock debris, and its minimum value can be calculated by the friction law:

$$
T=\left(P_{b}+\Delta P_{j}+w-P_{p}\right) \mu
$$

where $\mu$ is the dimensionless coefficient between matrix and rock debris.

When there is a pressure drop $\Delta P_{n}$ at the bottom of the well, equation (6) becomes

$$
T=\left(P_{b}+\Delta P_{j}+w-P_{p}-\Delta P_{n}\right) \mu .
$$

Equation (7) shows that when $P_{p}$ increases, the horizontal load $T$ decreases, which is more conducive to reducing the "chip hold-down effect" and improving rate of penetration. When the pulsation $P_{p}$ is large enough, $P_{b}+\Delta P_{j}+w-P_{p}+\Delta P_{n}<0$. At this time, there is no "chip hold-down effect" on the rock debris at bottom hole, and the rock debris will start to move automatically.

It is assumed that the initial pore pressure of bottom hole formation is $40 \mathrm{MPa}$, the fluid column pressure is $46 \mathrm{MPa}$, and the formation permeability coefficient is $1 \times 10^{-8} \mathrm{~m} / \mathrm{s}$. Apply sinusoidal pressure pulsation with frequency of $50 \mathrm{~Hz}$ and amplitude of $1 \mathrm{MPa}$ to the bottom hole and analyze the bottom hole relative negative pressure effect and mechanism of enhancing ROP under this pressure fluctuation.

Figure 14 shows the comparison of relative negative pressure generate at different positions on the bottom of the well. The figure shows that the relative negative pressure along the wellbore axis is the largest, the farther it is to the axis, the smaller the relative negative pressure is, and even there is only positive pressure at the edge of the bottom well. However, the shapes of the four curves in Figure 14 are similar, and any curve can be formed through the translation of other curve. This phenomenon is related to the attenuation rate of pore pressure at different positions on the bottom of the well. 


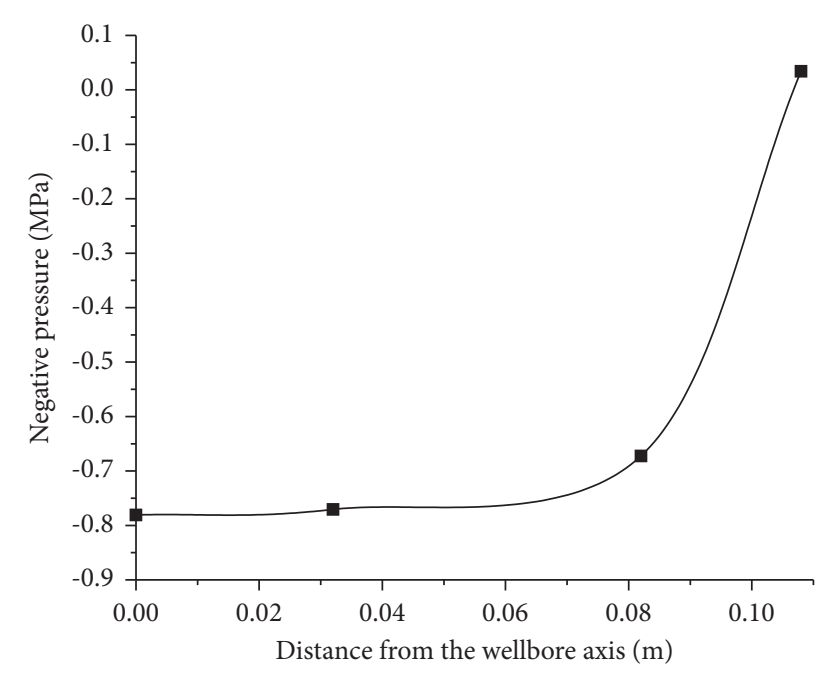

FIGURE 15: The maximum negative pressure in different positions.

Figure 15 shows that the maximum relative negative pressure gradually decreases with the increase of distance from the wellbore axis, and the initial decrease is slow. When it is near the wellbore wall, the relative negative pressure value decreases rapidly.

\section{Conclusion}

The effect of pulse frequency, pulse amplitude, formation initial pore pressure, and permeability coefficient on rock pore pressure is studied.

(1) With the increase of pulse frequency, the maximum value of bottom hole rock pore pressure gradually increases, but the growth rate is declining. The growth rate is very small in the range of $500 \mathrm{~Hz}$ to $5000 \mathrm{~Hz}$.

(2) The pulse amplitude mainly affects the bottom hole pressure and has little effect on the maximum pore pressure, but it affects the relative negative pressure.

(3) The initial pore pressure in the formation has little effect on the attenuation of bottom hole rock pore pressure and the relative negative pressure at bottom hole. It only changes the initial value of bottom hole pressure, which can be ignored in practical analysis.

(4) The permeability coefficient mainly affects the value of the relative negative pressure and the position of the maximum pore pressure. With the increase of permeability coefficient, the relative negative pressure decreases, and the position of negative pressure deepens gradually.

(5) The value of the relative negative pressure along the axis of the well is the largest, and the closer it gets to the wall, the less relative the negative pressure is.

\section{Data Availability}

The raw data used to support the findings of this study are available from the corresponding author upon request.

\section{Conflicts of Interest}

The authors declare that they have no conflicts of interest.

\section{Acknowledgments}

This study was sponsored by the Major Science and Technology Project of the CNPC under grant no. ZD2019-183005 .

\section{References}

[1] G. Li and H. Shi, "Mechanisms and tests for hydraulic pulsed cavitating jet assisted drilling," Petroleum Exploration and Development, vol. 35, p. 239, 2008.

[2] G. Li, H. Shi, J. Niu, Z. Huang, S. Tian, and X. Song, "Hydraulic pulsed cavitating jet assisted deep drilling: an approach to improve rate of penetration," in Proceedings of the International Oil and Gas Conference and Exhibition in China, pp. 197-207, OnePetro, Beijing,China, June 2010.

[3] M. R. Wells, "Dynamics of rock-chip removal by turbulent jetting," SPE Drilling Engineering, vol. 4, no. 02, pp. 144-152, 1989.

[4] M. Bizanti, "Jet pulsing may allow better hole cleaning," Oil \& Gas Journal, vol. 88, 1990.

[5] J.-Y. Xiong, "The mechanism of clearing away cuttings and breaking rocks using pulse jet nozzle," Natural Gas Industry, vol. 2, 1995.

[6] N. Cuiping, L. Xiangfang, Y. Dengsheng, Z. Zheng, and Z. Xiangfu, "Development and application of a drillable, lowfrequency and self-excited vibration pulsing cementing unit," Natural Gas Industry, vol. 32, pp. 74-76, 2012.

[7] W. Minghui, L. Gensheng, S. Huaizhong, S. Shuaishuai, L. Zhaokun, and Z. Yi, "Theories and applications of pulsedjet drilling with mechanical specific energy," SPE Journal, vol. 21, no. 1, pp. 303-310, 2016.

[8] S.-J. Chen, F. Feng, Y.-J. Wang et al., "Tunnel failure in hard rock with multiple weak planes due to excavation unloading of in-situ stress," Journal of Central South University, vol. 27, no. 10, pp. 2864-2882, 2020.

[9] F. Feng, S. Chen, Y. Wang, W. Huang, and Z. Han, "Cracking mechanism and strength criteria evaluation of granite affected by intermediate principal stresses subjected to unloading stress state," International Journal of Rock Mechanics and Mining Sciences, vol. 143, Article ID 104783, 2021.

[10] D. Xue, J. Zhou, Y. Liu, and L. Gao, "On the excavationinduced stress drop in damaged coal considering a coupled yield and failure criterion," International Journal of Coal Science \& Technology, vol. 7, no. 1, pp. 58-67, 2020.

[11] Y. Wang, H. Ni, Y. Tu et al., "Experimental study on axial impact mitigating stick-slip vibration with a PDC bit," Shock and Vibration, vol. 2021, Article ID 8897283, 8 pages, 2021.

[12] L. Peng, N. Hongiian, and W. Ruihe, "Field test of self-excited vibration rotary percussion drilling tool in deep and ultradeep wells," Petroleum Drilling Techniques, vol. 41, pp. 40-43, 2013.

[13] S. Liu, H. Ni, X. Wang, P. Wang, and N. Li, "Numerical study of the compound vertical and horizontal impact cutting with a single PDC cutter," Energy Reports, vol. 6, pp. 1520-1527, 2020.

[14] P. Lei, H.-J. Ni, R.-H. Wang et al., "Performance analysis and optimization for hydraulic components of self-oscillating rotary impact drilling tool," Journal of Vibration and Shock, vol. 33, pp. 175-198, 2014. 
[15] H.-J. Ni, R.-H. Wang, and Y.-Q. Zhang, "Numerical simulation study on rock breaking mechanism and process under high pressure water jet," Applied Mathematics and Mechanics, vol. 26, no. 12, pp. 1595-1604, 2005.

[16] Y. Du, R. Wang, and H. Ni, "Large eddy simulation of selfoscillation pulsed water jet drawing in annulus fluid," Journal of Hydrodynamics, vol. 24, pp. 455-462, 2009.

[17] G.-S. Li and Z.-H. Shen, "Advances in researches and applications of water jet theory in petroleum engineering," Petroleum Exploration and Development, vol. 4, p. 1, 2005.

[18] T. Chuanlin, H. Dong, and P. Jianghong, "Experimental study on the frequency characteristic of the self-excited oscillation pulsed nozzle," Acta Petrolei Sinica, vol. 28, p. 122, 2007.

[19] E. Detournay and A. H.-D. Cheng, "Poroelastic response of a borehole in a non-hydrostatic stress field," International Journal of Rock Mechanics and Mining Sciences \& Geomechanics Abstracts, Elsevier, vol. 25, no. 3, pp. 171-182, Netherland, 1988.

[20] S. Salehi, G. Hareland, and R. Nygaard, "Numerical simulations of wellbore stability in under-balanced-drilling wells," Journal of Petroleum Science and Engineering, vol. 72, no. 3-4, pp. 229-235, 2010.

[21] A. Kaffash and M. R. Zare-Reisabadi, "Borehole stability evaluation in overbalanced and underbalanced drilling: based on 3D failure criteria," Geosystem Engineering, vol. 16, no. 2, pp. 175-182, 2013.

[22] V. X. Nguyen, Y. N. Abousleiman, and S. K. Hoang, "Analyses of wellbore instability in drilling through chemically active fractured-rock formations," SPE Journal, vol. 14, no. 2, pp. 283-301, 2009.

[23] T. M. Warren and M. B. Smith, "Bottomhole stress factors affecting drilling rate at depth," Journal of Petroleum Technology, vol. 37, no. 8, pp. 1523-1533, 1985.

[24] T. Ito, K. Kurosawa, and K. Hayashi, "Stress concentration at the bottom of a borehole and its effect on borehole breakout formation," Rock Mechanics and Rock Engineering, vol. 31, no. 3, pp. 153-168, 1998.

[25] P. Ye, S. Zhonghou, and F. Shenghua, "Finite element model for analyzing stress field of bottom hole based on excavating method," Acta Petrolei Sinica, vol. 27, p. 133, 2006.

[26] R. Zhang, G.-S. Li, and S.-C. Tian, "Stress distribution and its influencing factors of bottom-hole rock in underbalanced drilling," Journal of Central South University, vol. 25, no. 7, pp. 1766-1773, 2018.

[27] L. Shibin, D. Tongwei, and D. Deren, "Stress state of bottomhole rocks in underbalanced drilling," Acta Petrologica Sinica, vol. 32, pp. 329-335, 2011.

[28] C. Deyu, L. Gensheng, S. Zhonghou, H. Zhongwei, T. Shouceng, and S. Huaizhong, "The stress field of bottom hole in deep and ultra-deep wells," Acta Petrolei Sinica, vol. 32, pp. 697-703, 2011.

[29] D. E. Beskos, "Dynamics of saturated rocks. I: equations of motion," Journal of Engineering Mechanics, vol. 115, no. 5, pp. 982-995, 1989. 